\title{
Antioxidant Capacity of Flavonoids in Hepatic Microsomes Is not Reflected by Antioxidant Effects In Vivo
}

\author{
Garry Duthie and Philip Morrice \\ Natural Products Group, Rowett Institute of Nutrition and Health, University of Aberdeen, Aberdeen AB21 9SB, UK \\ Correspondence should be addressed to Garry Duthie, g.duthie@rowett.ac.uk
}

Received 13 April 2012; Revised 6 June 2012; Accepted 8 June 2012

Academic Editor: Mohammad Abdollahi

Copyright (๑) 2012 G. Duthie and P. Morrice. This is an open access article distributed under the Creative Commons Attribution License, which permits unrestricted use, distribution, and reproduction in any medium, provided the original work is properly cited.

\begin{abstract}
Flavonoids are polyphenolic compounds with potential antioxidant activity via multiple reduction capacities. Oxidation of cellular lipids has been implicated in many diseases. Consequently, this study has assessed the ability of several dietary flavonoid aglycones to suppress lipid peroxidation of hepatic microsomes derived from rats deficient in the major lipid soluble antioxidant, d $\alpha$ tocopherol. Antioxidant effectiveness was galangin $>$ quercetin $>$ kaempferol $>$ fisetin $>$ myricetin $>$ morin $>$ catechin $>$ apigenin. However, none of the flavonoids were as effective as $\mathrm{d} \alpha$-tocopherol, particularly at the lowest concentrations used. In addition, there appears to be an important distinction between the in vitro antioxidant effectiveness of flavonoids and their ability to suppress indices of oxidation in vivo. Compared with $\mathrm{d} \alpha$-tocopherol, repletion of vitamin E deficient rats with quercetin, kaempferol, or myricetin did not significantly affect indices of lipid peroxidation and tissue damage. Direct antioxidant effect of flavonoids in vivo was not apparent probably due to low bioavailability although indirect redox effects through stimulation of the antioxidant response element cannot be excluded.
\end{abstract}

\section{Introduction}

Many polyphenols can act as antioxidants in chemical systems and food matrices as their extensive conjugated $\pi$ electron systems facilitate the donation of electrons from the hydroxyl moieties to oxidising radical species. For example, flavonoids which are formed via the plant phenylpropanoid pathway can have multiple reduction capacities. Reactivity, which is largely determined by the $\mathrm{O}-\mathrm{H}$ bond dissociation energies, is highly dependent on the configuration of the $\mathrm{O}-$ $\mathrm{H}$ groups of the $\mathrm{B}$ and $\mathrm{C}$ rings (Figure 1 ). Thus reaction stoichiometries for many common dietary-derived flavonoids exceed that of vitamin $\mathrm{E}$ ( $\mathrm{d} \alpha$-tocopherol), a major recognised antioxidant in biological systems [1]. The effectiveness of flavonoids as free radical scavengers in a wide range of chemical oxidation systems has resulted in suggestions that they may also have a role as dietary antioxidants which benefit health [2]. This is because the free radical mediated oxidation of proteins, lipids, and DNA is implicated in the pathogenesis of many diseases including heart disease and cancers [3]. However, many redox effects of flavonoids and other polyphenols observed in experimental systems may not be of biological relevance unless they gain access to tissues where they can exert hydrogen donating activity [4].

Whether flavonoids are redox active in vivo is a matter of debate. For example, several reviewed epidemiological studies have found inverse relationships between intake and diseases which involve oxidative stress [2]. However, a recent review concluded that there is little convincing evidence from human studies for a direct antioxidant effect of flavonoids or other polyphenols [5]. Such disparate views may reflect the diverse molecular structures of flavonoids within the food matrix. Commonly, they are glycosylated, methylated or acetylated at hydroxyl sites on their structure primarily at positions 3, 5, and 7. Such conjugation may not only decrease antioxidant effectiveness but may also impact on bioavailability so that ingested flavonoids pass into the colon relatively unabsorbed [6]. In contrast, lipophilic flavonoid aglycones in digested foods may enter cell membranes by simple diffusion potentially allowing hydrogen donation in oxidatively active cellular sites. For example, quercetin appears to be more bioavailable as an aglycone than as a glycoside when provided from dietary sources [7]. 


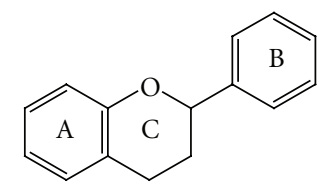<smiles>O=c1c(O)c(-c2ccc(O)c(O)c2)oc2cc(O)cc(O)c12</smiles><smiles>O=c1c(O)c(-c2ccc(O)cc2)oc2cc(O)cc(O)c12</smiles><smiles>CC(C)(C)C</smiles><smiles>O=c1cc(-c2ccc(O)cc2)oc2cc(O)cc(O)c12</smiles><smiles>Oc1cc(O)c2c(c1)O[C@H](c1ccc(O)c(O)c1)C(O)C2</smiles><smiles>O=c1c(O)c(-c2ccc(O)cc2O)oc2cc(O)cc(O)c12</smiles><smiles>O=c1c(O)c(-c2ccccc2)oc2cc(O)cc(O)c12</smiles><smiles>O=c1c(O)c(-c2ccc(O)c(O)c2)oc2cc(O)ccc12</smiles>

FIGURE 1: Basic flavonoid structure and structures of compounds used in the present study.

Aims. Increased indices of oxidation of cellular lipids are a characteristic of several diseases and nutritional antioxidant deficiencies [3]. Consequently, we have compared the ability of flavonoid aglycones and $\mathrm{d} \alpha$-tocopherol to inhibit lipid peroxidation of hepatic microsomes derived from rats deficient in vitamin E. In addition, we have determined the effects of consumption of three common dietary flavonoids in an oxidatively stressed rat model. Oxidative stress was induced by maintaining the rats for several weeks on diets deficient in vitamin $\mathrm{E}$. The effects in vivo of repletion with quercetin, myricetin, and kaempferol on indices of lipid peroxidation and tissue damage were compared with that of vitamin $\mathrm{E}$ and contrasted with antioxidant ability in vitro.

\section{Materials and Methods}

2.1. Microsomal Incubations. Vitamin E deficient microsomal incubations were as previously described [8]. In brief, livers were removed under terminal anaesthesia from male hooded Lister rats maintained for 12 weeks on a semisynthetic diet containing less than $0.5 \mathrm{mg}$ vitamin $\mathrm{E} / \mathrm{kg}$.
Microsomes were prepared and the protein concentration was adjusted to $10 \mathrm{mg} / \mathrm{mL}$ with $0.05 \mathrm{M}$ potassium phosphate buffer ( $\mathrm{pH} 7.4)$. Ethanolic solutions $(40 \mu \mathrm{L})$ of eight flavonoid aglycones or $\mathrm{d} \alpha$-tocopherol $(0.1,0.25$, and $0.5 \mathrm{mM}$ final concentrations) purchased from Fluka/Riedel-de Haën (Schwei Buchs, Switzerland) were incubated with $1 \mathrm{~mL}$ microsomal suspensions for $20 \mathrm{~min}$ at $25^{\circ} \mathrm{C}$ on an asymmetric roller. Peroxidation was then initiated with an ascorbate/ $\mathrm{Fe}^{2+} / \mathrm{ADP}$ complex [8], and aliquots removed for determination of thiobarbituric acid reactive substances (TBARS) by HPLC [9]. From the oxidation curves, the relative abilities of the flavonoids to delay oxidation (lag phase) and suppress maximum peroxidation was calculated relative to the vitamin $\mathrm{E}$ deficient microsomes [8].

2.2. In Vivo Model. The study protocol was conducted in compliance with the Animals (Scientific Procedures) Act, 1986 , and the format is previously described $[9,10]$. Weanling male rats were randomly allocated to 5 intervention groups of 6 animals each. Four intervention groups were offered, ad libitum, the vitamin $\mathrm{E}$ deficient semisynthetic 
diet for 10 weeks. Rats were then offered this diet supplemented with either $\mathrm{d} \alpha$-tocopherol, quercetin, myricetin, or kaempferol at a concentration of $100 \mathrm{mg} / \mathrm{kg}$ diet for a further 2 weeks. These compounds were selected as current food compositional databases [11] suggest that they are the most commonly consumed flavonols in the N. European diet. The amount incorporated into the rat chow was selected as reflecting that which is nutritionally achievable by humans by dietary means [11] as the current study was not aimed at establishing responses to pharmaceutical concentrations. The compounds were dissolved in chloroform and mixed to an even distribution in the diet. The remaining rats were maintained on the vitamin $\mathrm{E}$ deficient ration. After 12 weeks, (when 16 weeks old and weighing approximately $400 \mathrm{~g}$, see Table 3) the rats were terminally anaesthetized and blood samples were collected by cardiac puncture into heparinized tubes. Plasma was separated by centrifugation for $15 \mathrm{~min}$ at $1750 \mathrm{~g}, 4^{\circ} \mathrm{C}$, and red cells were isolated and washed twice prior to being re-suspended to the original volume in phosphate buffered saline. The liver was perfused in situ with chilled isotonic $\mathrm{KCl}(0.154 \mathrm{M})$ via the hepatic portal vein and snap frozen in liquid nitrogen before storage at $-80^{\circ} \mathrm{C}$ until analysis. Plasma concentrations of vitamin $\mathrm{E}$, quercetin, myricetin, and kaempferol were determined by HPLC using previously described procedures $[12,13]$. Plasma levels of TBARS were determined by HPLC with fluorimetric detection [9]. Functional antioxidant status was estimated by the susceptibility of washed erythrocytes to hydrogen peroxide-induced peroxidation [14] and by an electron paramagnetic resonance procedure with spin trapping of lipid radicals with 4-POBN in liver homogenates [15]. Plasma pyruvate kinase (PK) activities were measured as indices of tissue damage by the method of Chow [16].

2.3. Statistical Analysis. Results are presented as mean \pm SEM. Data were initially analysed by one-way analysis of variance and comparison of groups of rats was made using the Bonferroni multiple comparison test. A $P$ value of less than 0.05 was considered significant.

\section{Results}

In general, an observed time-dependent increase in lipid peroxidation of the hepatic microsomal preparations derived from vitamin $\mathrm{E}$ deficient rats was moderated by preincubation with ethanolic solutions of flavonoids. Protection against peroxidation increased with increased concentration of flavonoid as shown for quercetin (Figure 2).

Interpolation of the incubation curves to quantify the data as the ability to delay the onset of peroxidation (Table 1) and the suppress maximum peroxidation (Table 2) compared with that of microsomes without flavonoid addition indicated antioxidant effectiveness as galingen $>$ quercetin $>$ kaempferol $>$ fisetin $>$ myricetin $>$ morin $>$ catechin $>$ apigenin. However, none of the flavonoids were as effective as $\mathrm{d} \alpha$-tocopherol, particularly at the lowest concentration of $0.1 \mathrm{mM}$ (Tables 1 and 2).

In the animal model, repletion with diets containing quercetin and kaempferol was associated with the presence
TABLE 1: Abilities of polyphenol aglycones and $\mathrm{d} \alpha$-tocopherol to delay the onset of peroxidation (lag phase) of hepatic microsomal preparations from vitamin $\mathrm{E}$ deficient rats.

\begin{tabular}{lccc}
\hline Compound & \multicolumn{3}{c}{ Lag phase (min) } \\
& $0.1 \mathrm{mM}$ & $>25 \mathrm{mM}$ & $0.5 \mathrm{mM}$ \\
\hline Quercetin & 8.7 & 19.8 & $>20$ \\
Kaempferol & 7.8 & 12.6 & $>20$ \\
Myricetin & 7.0 & 4.7 & 14.3 \\
Apigenin & 4.7 & 5.9 & 4.8 \\
Catechin & 5.8 & 7.4 & 6.2 \\
Morin & 4.1 & $>20$ & 9.6 \\
Galingin & 3.3 & 15.0 & $>20$ \\
Fisetin & 4.9 & $>20$ & $>20$ \\
d $\alpha$-tocopherol & $>20$ & $>20$ \\
\hline
\end{tabular}

Peroxidation was initiated with an ascorbate/ $\mathrm{Fe}^{2+} / \mathrm{ADP}$ complex and estimated by the formation of thiobarbituric acid substances (TBARS) as described in Section 2. Values are means of duplicate determinations.

TABLE 2: Abilities of polyphenol aglycones and $\mathrm{d} \alpha$-tocopherol to inhibit maximum peroxidation of hepatic microsomal preparations from vitamin E deficient rats.

\begin{tabular}{lccc}
\hline Compound & \multicolumn{3}{c}{$\begin{array}{c}\text { Inhibition (\%) } \\
0.25 \mathrm{mM}\end{array}$} \\
\hline Quercetin & 38 & 87 & $0.5 \mathrm{mM}$ \\
Kaempferol & 21 & 88 & 95 \\
Myricetin & 11 & 67 & 95 \\
Apigenin & 1 & 1 & 60 \\
Catechin & 1 & 1 & 0 \\
Morin & 7 & 13 & 1 \\
Galingin & 13 & 88 & 44 \\
Fisetin & 10 & 68 & 94 \\
d $\alpha$-tocopherol & 93 & 97 & 90 \\
\hline
\end{tabular}

Peroxidation was initiated with an ascorbate/ $\mathrm{Fe}^{2+} / \mathrm{ADP}$ complex and estimated by the formation of thiobarbituric acid substances (TBARS) as described in Section 2. Values are means of duplicate determinations.

of the flavonoids in plasma of vitamin $\mathrm{E}$ deficient rats. However, no myricetin was detected in any of the rats even when provided with the flavonoid in the diet for 2 weeks. However, repletion with a similar concentration of dietary $\mathrm{d} \alpha$-tocopherol resulted in a marked increase of the compound in plasma which was an order of magnitude greater than any of the detected flavonoids (Table 3 ).

Repletion of the vitamin E deficient rats with $100 \mathrm{mg}$ $\mathrm{d} \alpha$-tocopherol/kg diet resulted in a significant decrease in concentrations of TBARS in both plasma $(P<0.05)$ and liver $(P<0.001)$. In contrast, concentrations were unaffected by repletion with similar amounts of either quercetin, kaempferol, and myricetin (Table 4). Repletion with $\mathrm{d} \alpha$ tocopherol was also associated with a marked decrease in membrane damage as indicated by lower activities of pyruvate kinase in plasma and by decreases in the functional markers of oxidative susceptibility, namely, erythrocyte lipid peroxidation, and hepatic tissue EPR signal height. However, 


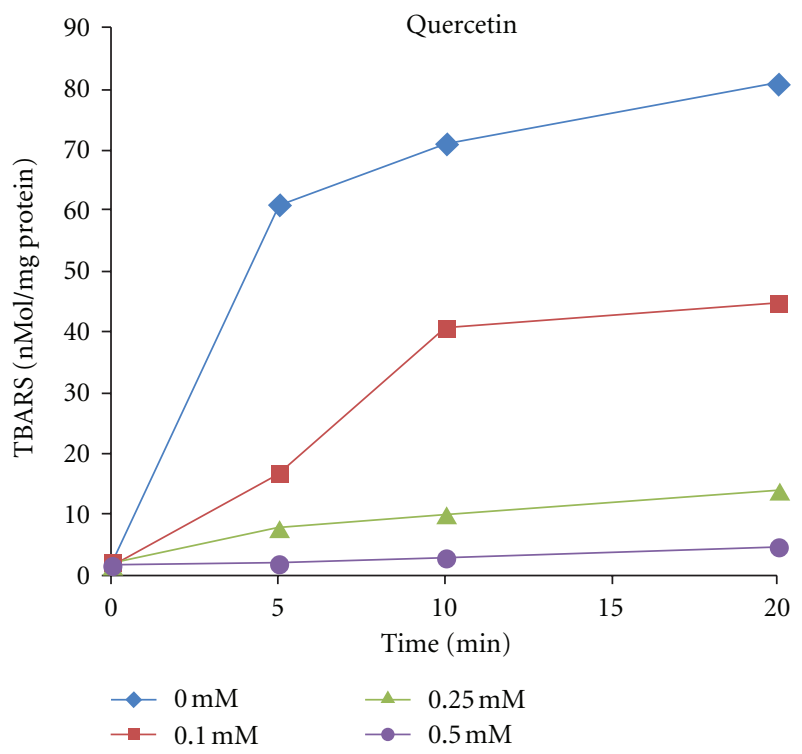

FIGURE 2: Example of preincubation of hepatic microsomal preparations from vitamin E deficient rats with a polyphenol aglycone (quercetin) on production of thiobarbituric reactive substances (TBARS) following initiation of peroxidation with Fe/ADP.

TABLE 3: Weights and plasma concentrations of flavonoids and $\alpha$-tocopherol in vitamin E deficient rats repleted for 2 weeks with $100 \mathrm{mg} / \mathrm{kg}$ of either $\alpha$-tocopherol, quercetin, kaempferol or myricetin.

\begin{tabular}{|c|c|c|c|c|c|}
\hline \multirow{2}{*}{ Parameter } & \multicolumn{5}{|c|}{ Dietary inclusion } \\
\hline & -Vitamin E & $+\mathrm{d} \alpha$-tocopherol & +Quercetin & +Kaempferol & + Myricetin \\
\hline Weight (g) & $398 \pm 11$ & $394 \pm 14$ & $393 \pm 11$ & $398 \pm 9$ & $397 \pm 7$ \\
\hline $\mathrm{d} \alpha$-tocopherol $(\mathrm{nmol} / \mathrm{L})$ & $1.16 \pm 0.12$ & $12.91 \pm 0.12^{*}$ & $0.91 \pm 0.12$ & $1.00 \pm 0.07$ & $1.04 \pm 0.09$ \\
\hline Quercetin $(\mu \mathrm{mol} / \mathrm{L})$ & Trace & Trace & $1.48 \pm 0.18$ & Trace & Trace \\
\hline Kaempferol $(\mu \mathrm{mol} / \mathrm{L})$ & Trace & Trace & Trace & $0.47 \pm 0.06$ & Trace \\
\hline Myricetin $(\mu \mathrm{mol} / \mathrm{L})$ & nd & nd & nd & nd & nd \\
\hline
\end{tabular}

Results are mean \pm SEM of 6 rats/group. ${ }^{*}$ Significantly different from - Vitamin E group $(P<0.001)$. Trace indicates that peak heights were too small to quantify; nd: no detectable compound.

TABLE 4: Effects of 2 weeks repletion with either $100 \mathrm{mg} \alpha$-tocopherol, quercetin, kaempferol or myricetin/kg diet on indices of muscle damage, lipid peroxidation and antioxidant capacity of vitamin E deficient rats.

\begin{tabular}{|c|c|c|c|c|c|}
\hline \multirow{2}{*}{ Parameter } & \multicolumn{5}{|c|}{ Dietary inclusion } \\
\hline & -Vitamin E & $+\mathrm{d} \alpha$-tocopherol & +Quercetin & +Kaempferol & + Myricetin \\
\hline Pyruvate kinase (U/L) & $807 \pm 76$ & $132 \pm 13^{* * *}$ & $632 \pm 98$ & $617 \pm 108$ & $742 \pm 81$ \\
\hline TBARS (nmol/mL plasma) & $1.66 \pm 0.13$ & $1.13 \pm 0.09^{*}$ & $2.14 \pm 0.51$ & $2.33 \pm 0.34$ & $2.08 \pm 0.21$ \\
\hline TBARS (nmol/mg hepatic protein) & $15.3 \pm 0.7$ & $2.4 \pm 0.6^{* * *}$ & $13.4 \pm 0.5$ & $13.8 \pm 0.8$ & $12.5 \pm 0.3$ \\
\hline Erythrocyte lipid peroxidation (nmol/mgHb) & $50 \pm 7$ & $3 \pm 1^{* * *}$ & $53 \pm 4$ & $63 \pm 5$ & $64 \pm 4$ \\
\hline EPR signal height (RU/mg hepatic protein) & $22423 \pm 1133$ & $1036 \pm 71^{* * *}$ & $19950 \pm 1458$ & $18833 \pm 448$ & $17425 \pm 1892$ \\
\hline
\end{tabular}

Results are mean \pm SEM of 6 rats/group. Significantly different from - Vitamin E group $\left({ }^{*} P<0.05 ; * * *<0.001\right)$. TBARS: thiobarbituric acid reactive substances $\mathrm{Hb}$ : haemoglobin, EPR: Electron paramagnetic resonance spectroscopy, RU: relative units.

no analogous effects on these indices were observed in those rats that were fed any of the flavonoids (Table 4).

\section{Discussion}

The ability of many of the flavonoids to inhibit peroxidation of hepatic microsomal preparations from vitamin E deficient rats might indicate that these dietary compounds could have significant "vitamin E-like" activity in biological systems. As in chemical systems [2, 17], antioxidant potency may depend in part on the number and position of the $\mathrm{OH}$ groups on the molecule. For example, using a DPPH radical scavenging system, structure-activity studies indicate that the O-dihydroxy group on ring $\mathrm{B}$ of flavonoids plays a crucial role. A double bond at 2-3 position conjugated with a 4-oxo function and hydroxyl groups at positions 3 and 
5 also contribute towards antiradical activity of flavonoids [17]. However, within biological samples such as tissue homogenates, antioxidant activity may differ from structurefunction relationships apparent in chemical systems [8, 17]. Other factors including molecular charge, solubility, and partitioning coefficients may also be important determinants of antioxidant activity. Within microsomal membranes, in particular, appropriate orientation of the compound within the membranes to allow access of hydroxyl groups to peroxyl radicals within phospholipid moieties may be relevant. This may explain the greater efficacy of $\mathrm{d} \alpha$-tocopherol at the lower concentration as the phytol chain may intercalate within the membrane thus conferring optimum orientation of $\mathrm{OH}$ groups on the chromanol ring structure [18].

There appears to be an important distinction between the in vitro antioxidant effectiveness of flavonoids and their ability to suppress indices of oxidation in vivo. Compared with $\mathrm{d} \alpha$-tocopherol, repletion of vitamin $\mathrm{E}$ deficient rats with quercetin, kaempferol or myricetin did not significantly affect indices of lipid peroxidation and tissue damage in plasma and liver. This likely reflects the relatively low bioavailability and/or rapid systemic clearance of the aglycones as their inclusion in the diet did not result in marked increase in concentrations in plasma. Studies aimed at elucidating the degree and mechanisms of the absorption of flavonoid aglycones are contradictory [7, 19, 20], but recent reviews indicate that bioavailability is mostly $<1 \%$ of the administered dose [21]. Consequently, the dietary relevant concentrations used in the present study may be insufficient to illicit an antioxidant effect in vivo. Bioactivity may only be apparent at greater doses which are not nutritionally achievable. For example, decreased serum TBARS has been observed in rats fed 2-10-fold greater doses of quercetin than used in the present study [22]. However, the results of the present study support previous observations of limited in vivo bioactivity of dietary flavonoids. For example, studies in growing rats did not show any vitamin E sparing effects of flavonoids such as quercetin and catechin [23], and supplementation of pigs with green tea polyphenols did not enhance tissue vitamin E levels or plasma antioxidant capacity [24]. Moreover, consumption of green tea extracts for 3 weeks did not influence plasma vitamin E concentrations and cardiovascular risk markers in healthy men [25].

In conclusion, several flavonoid aglycones effectively suppressed lipid peroxidation of microsomal preparations but analogous effects were not observed in vivo. Consequently, quercetin, myricetin, and kaempferol are not effective nutritional antioxidants in the vitamin $\mathrm{E}$ deficient rat model when compared with the effectiveness of $\mathrm{d} \alpha$-tocopherol. However, in the present study we did not determine potential metabolites derived from the compounds. Consequently indirect redox effects not involving suppression of lipid peroxidation such as stimulation of the antioxidant response element cannot be excluded [26]. Never the less, results of the present study support the conclusion of a recent review [5] that a direct antioxidant effect of flavonoids in vivo with dietary achievable intakes is questionable. This does not exclude the possibility that the marked antioxidant efficacy of some flavonoids in vitro can be exploited in future drug development aimed at addressing clinical conditions where oxidative stress is an underlying pathology. For example, a systematic review of medicinal plants used in folk medicine [27] indicated that several increased serum antioxidant capacity and/or decreased indices of lipid peroxidation in animals and humans. Whether such effects can be ascribed to flavonoids per se is currently unclear. However, studies assessing their use as potential chemopreventative agents appear warranted.

\section{Acknowledgments}

The authors are grateful for support from The Scottish Government (RESAS) Healthy Safe Diets Programme and from the EU FAIR Natural Antioxidants in Food Programme (Grant no. 0158).

\section{References}

[1] D. B. McPhail, R. C. Hartley, P. T. Gardner, and G. G. Duthie, "Kinetic and stoichiometric assessment of the antioxidant activity of flavonoids by electron spin resonance spectroscopy," Journal of Agricultural and Food Chemistry, vol. 51, no. 6, pp. 1684-1690, 2003.

[2] P. G. Pietta, "Flavonoids as antioxidants," Journal of Natural Products, vol. 63, no. 7, pp. 1035-1042, 2000.

[3] O. I. Aruoma, "Free radicals, oxidative stress, and antioxidants in human health and disease," Journal of the American Oil Chemists' Society, vol. 75, no. 2, pp. 199-212, 1998.

[4] G. G. Duthie, "Determination of activity of antioxidants in human subjects," Proceedings of the Nutrition Society, vol. 58, no. 4, pp. 1015-1024, 1999.

[5] P. C. H. Hollman, A. Cassidy, B. Comte et al., "The biological relevance of direct antioxidant effects of polyphenols for cardiovascular health in humans is not established," Journal of Nutrition, vol. 141, no. 5, 2011.

[6] J. Kyle and G. G. Duthie, "Nutritional relevance of flavonoids in disease prevention," Natural Products Communications, no. 11, pp. 1049-1060, 12006.

[7] W. Wiczkowski, J. Romaszko, A. Bucinski et al., "Quercetin from shallots (Allium cepa L. var. aggregatum) is more bioavailable than its glucosides," Journal of Nutrition, vol. 138, no. 5, pp. 885-888, 2008.

[8] J. H. Mitchell, P. T. Gardner, D. B. McPhail, P. C. Morrice, A. R. Collins, and G. G. Duthie, "Antioxidant efficacy of phytoestrogens in chemical and biological model systems," Archives of Biochemistry and Biophysics, vol. 360, no. 1, pp. 142-148, 1998.

[9] C. Ramirez-Tortosa, Ø. M. Andersen, P. T. Gardner et al., "Anthocyanin-rich extract decreases indices of lipid peroxidation and DNA damage in vitamin E-depleted rats," Free Radical Biology and Medicine, vol. 31, no. 9, pp. 1033-1037, 2001.

[10] S. J. Duthie, P. T. Gardner, P. C. Morrice et al., "DNA stability and lipid peroxidation in vitamin E-deficient rats in vivo and colon cells in vitro: modulation by the dietary anthocyanin, cyanidin-3-glycoside," European Journal of Nutrition, vol. 44, no. 4, pp. 195-203, 2005.

[11] J. A. M. Kyle and G. G. Duthie, "Flavonoids in foods," in Flavonoids: Chemistry, Biochemistry and Applications, M. Ø. Andersen and K. R. Markam, Eds., p. 219, Taylor and Francis Group, Boca Raton, Fla, USA, 2006. 
[12] P. C. Morrice, S. G. Wood, and G. G. Duthie, "Highperformance liquid chromatographic determination of quercetin and isorhamnetin in rat tissues using $\beta$-glucuronidase and acid hydrolysis," Journal of Chromatography B, vol. 738, no. 2, pp. 413-417, 2000.

[13] J. A. M. Kyle, P. C. Morrice, G. McNeill, and G. G. Duthie, "Effects of infusion time and addition of milk on content and absorption of polyphenols from black tea," Journal of Agricultural and Food Chemistry, vol. 55, no. 12, pp. 48894894, 2007.

[14] G. G. Duthie, J. R. Arthur, P. Bremner, Y. Kikuchi, and F. Nicol, "Increased peroxidation of erythrocytes of stress-susceptible pigs: an improved diagnostic test for porcine stress syndrome," American Journal of Veterinary Research, vol. 50, no. 1, pp. 8487, 1989.

[15] G. D. Duthie, D. B. McPhail, J. R. Arthur, B. A. Goodman, and P. C. Morrice, "Spin trapping of free radicals and lipid peroxidation in microsomal preparations from malignant hyperthermia susceptible pigs," Free Radical Research Communications, vol. 8, no. 2, pp. 93-99, 1990.

[16] C. K. Chow, "Increased activity of pyruvate kinase in plasma of vitamin E deficient rats," Journal of Nutrition, vol. 105, no. 9, pp. 1221-1224, 1975.

[17] K. L. Khanduja and A. Bhardwaj, "Stable free radical scavenging and antiperoxidative properties of resveratrol compared in vitro with some other bioflavonoids," Indian Journal of Biochemistry and Biophysics, vol. 40, no. 6, pp. 416-422, 2003.

[18] C. J. Bennett, S. T. Caldwell, D. B. McPhail, P. C. Morrice, G. G. Duthie, and R. C. Hartley, "Potential therapeutic antioxidants that combine the radical scavenging ability of myricetin and the lipophilic chain of vitamin E to effectively inhibit microsomal lipid peroxidation," Bioorganic and Medicinal Chemistry, vol. 12, no. 9, pp. 2079-2098, 2004.

[19] V. Crespy, C. Morand, C. Besson, C. Manach, C. Demigne, and C. Remesy, "Quercetin, but not its glycosides, is absorbed from the rat stomach," Journal of Agricultural and Food Chemistry, vol. 50, no. 3, pp. 618-621, 2002.

[20] P. C. H. Hollman, M. N. C. P. Bijsman, Y. Van Gameren, E. P. J. Cnossen, J. H. M. De Vries, and M. B. Katan, "The sugar moiety is a major determinant of the absorption of dietary flavonoid glycosides in man," Free Radical Research, vol. 31, no. 6, pp. 569-573, 1999.

[21] C. Manach, G. Williamson, C. Morand, A. Scalbert, and C. Rémésy, "Bioavailability and bioefficacy of polyphenols in humans. I. Review of 97 bioavailability studies," The American journal of clinical nutrition, vol. 81, no. 1, 2005.

[22] Y. Nakamura, S. Ishimitsu, and Y. Tonogai, "Effects of quercetin and rutin on serum and hepatic lipid concentrations, fecal steroid excretion and serum antioxidant properties," Journal of Health Science, vol. 46, no. 4, pp. 229-240, 2000.

[23] H. Wiegand, C. Boesch-Saadatmandi, S. Wein, S. Wolffram, J. Frank, and G. Rimbach, "Dietary flavonoids do not affect vitamin E status in growing rats," Journal of Animal Physiology and Animal Nutrition, vol. 94, no. 3, pp. 307-318, 2010.

[24] K. Augustin, R. Blank, C. Boesch-Saadatmandi, J. Frank, S. Wolffram, and G. Rimbach, "Dietary green tea polyphenols do not affect vitamin E status, antioxidant capacity and meat quality of growing pigs," Journal of Animal Physiology and Animal Nutrition, vol. 92, no. 6, pp. 705-711, 2008.

[25] J. Frank, T. W. George, J. K. Lodge et al., "Daily consumption of an aqueous green tea extract supplement does not impair liver function or alter cardiovascular disease risk biomarkers in healthy men," Journal of Nutrition, vol. 139, no. 1, pp. 5862, 2009.

[26] R. Masella, R. Di Benedetto, R. Varì, C. Filesi, and C. Giovannini, "Novel mechanisms of natural antioxidant compounds in biological systems: involvement of glutathione and glutathione-related enzymes," Journal of Nutritional Biochemistry, vol. 16, no. 10, pp. 577-586, 2005.

[27] S. Hasani-Ranjbar, B. Larijani, and M. Abdollahi, "A systematic review of the potential herbal sources of future drugs effective in oxidant-related diseases," Inflammation and Allergy, vol. 8, no. 1, pp. 2-10, 2009. 


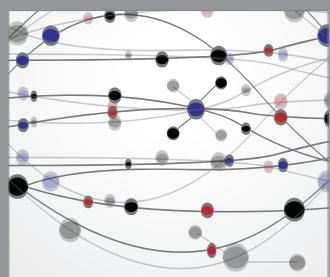

The Scientific World Journal
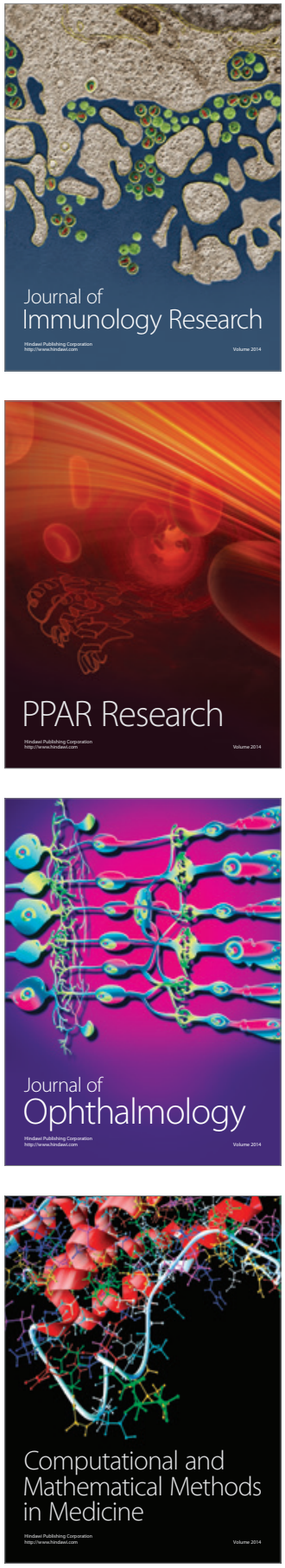

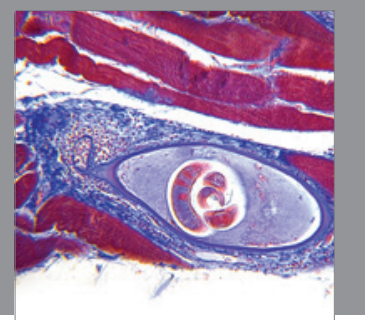

Gastroenterology

Research and Practice
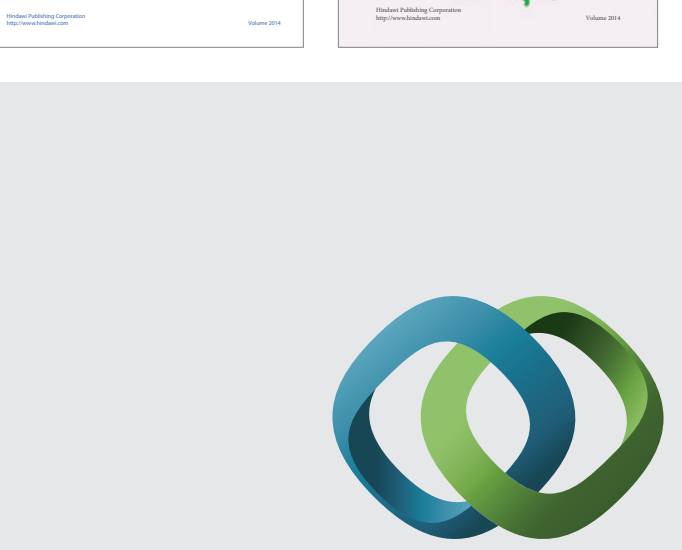

\section{Hindawi}

Submit your manuscripts at

http://www.hindawi.com
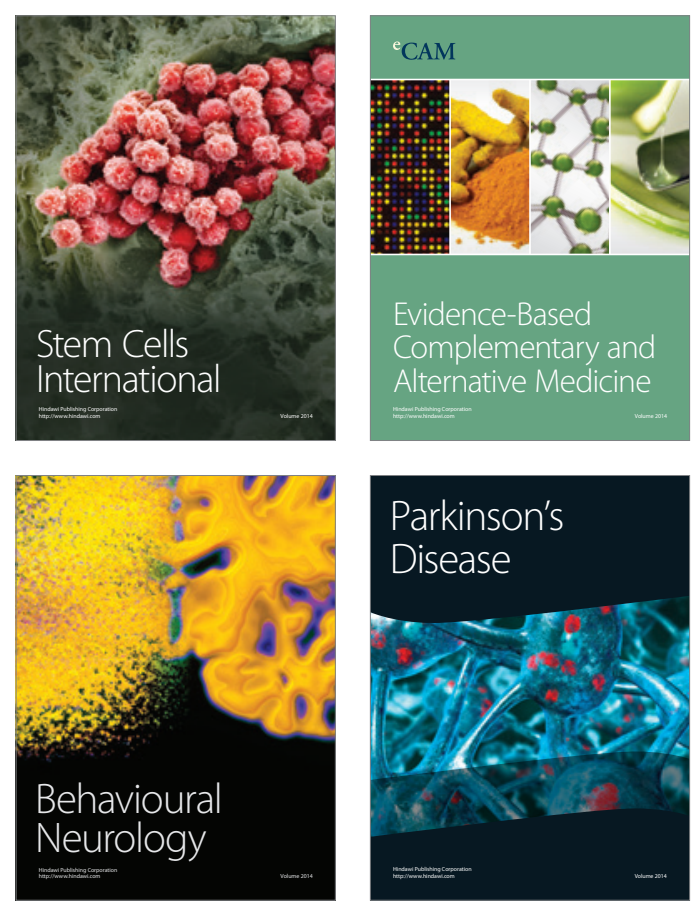

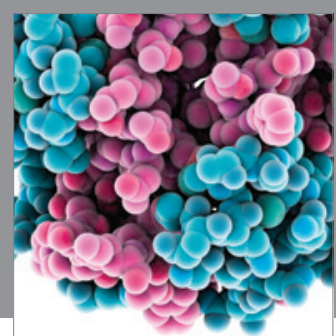

Journal of
Diabetes Research

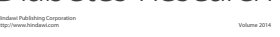

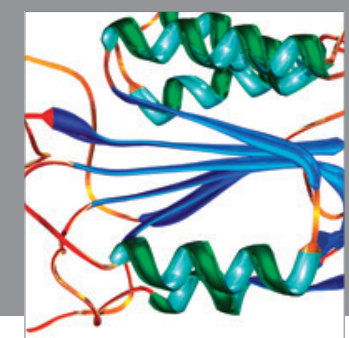

Disease Markers
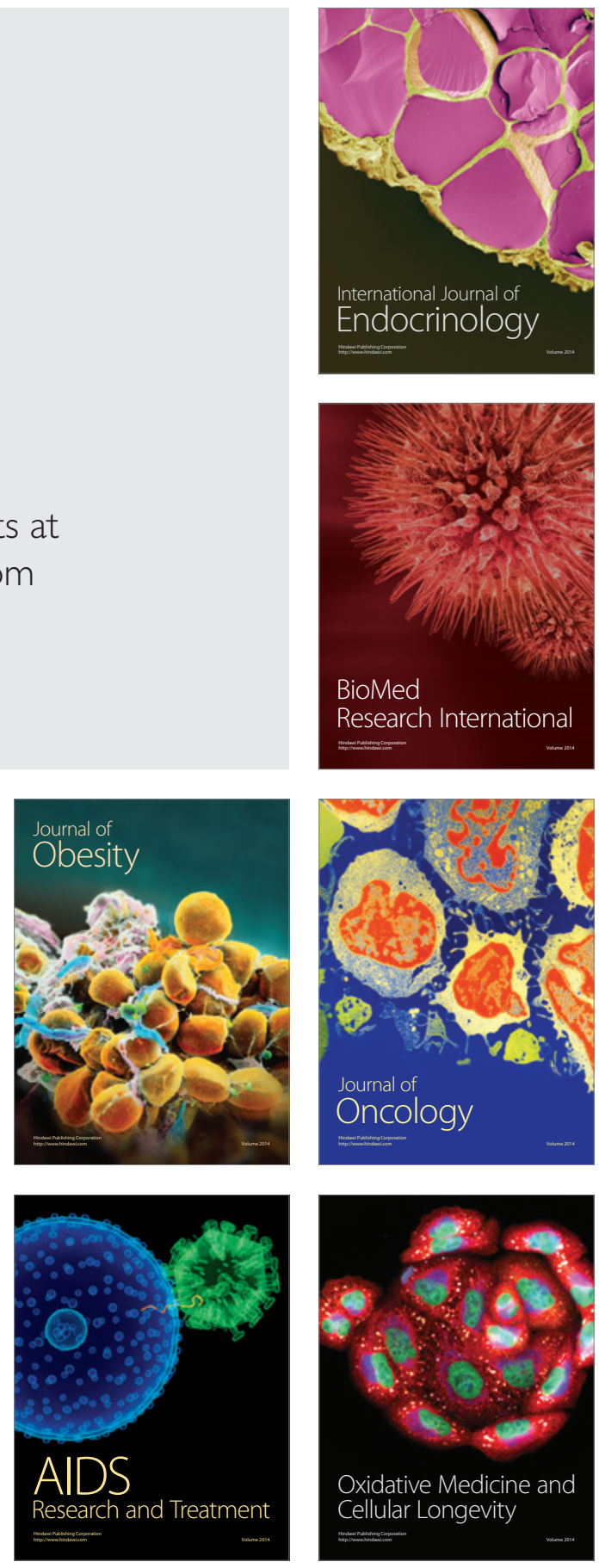